\title{
Beyond technology: A scoping review of features that promote fidelity and authenticity in simulation-based health professional education
}

LAVOIE, Patrick (patrick.lavoie.1@umontreal.ca) ${ }^{\text {ab }}$

DESCHÊNES, Marie-France (marie-france.deschenes@umontreal.ca) ${ }^{a}$

NOLIN, Roxane (roxane.nolin@umontreal.ca) ${ }^{a}$

BÉLISLE, Marilou (marilou.e.belisle@usherbrooke.ca) ${ }^{c}$

BLANCHET GARNEAU, Amélie (amelie.blanchet.garneau@ umontreal.ca) a

BOYER, Louise (louise.boyer@umontreal.ca) ${ }^{\text {a }}$

LAPIERRE, Alexandra (alexandra.lapierre@umontreal.ca) ${ }^{\text {a }}$

FERNANDEZ, Nicolas (nicolas.fernandez@umontreal.ca) ${ }^{\mathrm{d}}$

a. Center for Innovation in Nursing Education (CIFI), Faculty of Nursing, Université de Montréal, C.P. 6128, succ. Centre-Ville, Montreal QC, Canada, H3C 3J7

b. Montreal Heart Institute Research Center, 5000, rue Bélanger, Montreal QC, Canada, H1T 1 C8

c. Faculty of Education, Université de Sherbrooke, 150, place Charles-Le Moyne, Bureau 200, Longueuil QC, Canada, J4K 0A8

d. Departement of Family Medicine and Emergency Medicine, Faculty of Medicine, Université de Montréal, C.P. 6128, succ. Centre-Ville, Montreal QC, Canada, H3C 3J7

Corresponding author: Patrick Lavoie (patrick.lavoie.1@umontreal.ca) 


\begin{abstract}
Background: Conceptualizations of fidelity in simulation often refer to physical, conceptual, and psychological dimensions. Besides simulator technologies, practical features that enhance the fidelity and authenticity of simulated activities from educators' and learners' perspectives remain nebulous.
\end{abstract}

Methods: Scoping review (Levac, Colquhoun, \& O'Brien, 2010).

Results: From 42 papers, eight features were identified: content drawn from real life, interaction and feedback, performance expectations, preparation of the environment, presence of an actual patient, logical and adaptive scenarios, sociological fidelity, and cueing.

Conclusions: This paper provides guidance in the design of high-fidelity, authentic simulations, even in the absence of technologically advanced simulators.

Keywords: Simulation; realism, fidelity, authenticity; health education; scoping review

\title{
HIGHLIGHTS
}

- Eight features that foster simulation fidelity are identified

- These features also contribute to learners' experience of authenticity

- They can guide the design of realistic simulations when technology is scarce

\section{KEY POINTS}

- Fidelity is often equated to the engineering attributes of simulation equipment and used interchangeably with the concepts of 'authenticity' and 'realism'.

- Eight features that promote fidelity or authenticity in simulation-based education are identified, beside technological or engineering attributes of simulation equipment.

- Features include: drawing content from real life, providing opportunities for interaction and feedback, requiring learners to perform actions, preparing the environment to engage learners' senses, including an actual patient, presenting a logical and adaptive scenario, reproducing sociological aspects of the real world, and cueing. 


\section{INTRODUCTION}

Simulation is an active educational method that consists of replacing real experiences with guided experiences that replicate aspects of the real world in an interactive manner (Gaba, 2004). For educators, simulation provides an opportunity to determine the situations that learners will experience. This opportunity comes with an imperative to portray those situations in a realistic manner, in order to provide an engaging and immersive learning experience. Accordingly, fidelity has become an important topic in the simulation literature.

'Fidelity' refers to the degree of realism of a simulation and includes physical, conceptual, and psychological dimensions (INACSL Standards Committee, 2016). However, fidelity is often equated with the technology employed for simulation, thereby overemphasizing engineering attributes of equipment over educational implications. This vision has been criticized by a number of authors (Beaubien \& Baker, 2004; Bland, Topping, \& Tobbell, 2014; Hamstra, Brydges, Hatala, Zendejas, \& Cook, 2014; Norman, Dore, \& Grierson, 2012; Tun, Alinier, Tang, \& Kneebone, 2015; West, Beaumie, \& Parchoma, 2017). In a literature review, Norman et al. (2012) found clear benefits of simulation over other forms of instruction, but little advantages of high engineering fidelity (e.g., computer-controlled manikins) over low engineering fidelity for learning of technical and non-technical skills. Sherwood and Francis (2018) came to similar conclusions in a metaanalysis that revealed small benefits of high versus low engineering fidelity for knowledge, psychomotor, affective, and non-technical outcomes. As Norman et al. (2012) suggested, this could reflect the nonlinear relationship between fidelity and learning, and the multidimensional nature of the concept. This suggests a need to conduct a literature review to clarify the various dimensions of fidelity and the features that contribute to its enactment in simulation-based learning. 


\section{CURRENT STATE OF KNOWLEDGE}

In early years, fidelity was equated with the resemblance of a simulator to the actual task or equipment it portrayed (Allen, Buffardi, \& Hays, 1991). Nowadays, it is generally acknowledged that fidelity refers to the degree to which various aspects of a simulation combine to mimic reality (Bland et al., 2014). Rehmann, Mitman, and Reynolds (1995) proposed a three-dimension typology of fidelity, which was further described by Beaubien and Baker (2004). The first dimension, 'equipment fidelity', refers to the appearance and feel of a simulator. The second, 'environment fidelity', is concerned with the cues and other sensory information that are available to the learner in the environment surrounding the simulator. The third, 'psychological fidelity', is the degree to which learners believe in a simulation (i.e., how they perceived the simulation to be a credible surrogate for an authentic task or problem). Similarly, Dieckmann, Gaba, and Rall (2007) proposed three modes of thinking about reality to describe simulation fidelity: 'physical' (characteristics of the environment, equipment, and material), 'semantic' (presentation of information and relationships between concepts), and 'phenomenal' (learners' emotions, beliefs, and thoughts).

Recently, Tun et al. (2015) suggested defining the concept of fidelity according to learners' perceived realism of a simulation instead of the technology used. They argued that fidelity requires an accurate representation of real-world cues along three axes: 1) interactions with the patient, bearing in mind anatomy and physiology; 2) progression and complexity of the scenario; and 3) healthcare facilities (i.e., clinical equipment and environment). In a discussion of simulation-based interprofessional education, Sharma, Boet, Kitto, and Reeves (2011) introduced the concept of 'sociological fidelity', arguing that the transfer of interprofessional skills to clinical practice depends on the proper reproduction of sociological issues affecting teamwork, such as power, hierarchy, and professional boundaries. For their part, Hamstra et al. (2014) suggested avoiding the term 'fidelity' and prioritizing functional task alignment (i.e., replication of the demands of a real 
clinical task) over physical resemblance. To maximize educational effectiveness of simulation, they recommended focusing on broader design principles and methods to engage learners and promote transfer of learning to clinical practice, which include not only resemblance to reality but also learner orientation and focused learning objectives.

Beside these various dimensions, the notion of 'authenticity' is often associated with the concept of fidelity. Nevertheless, the two terms are not conceptually equivalent: fidelity can be considered as the degree of reproduction of reality, whereas authenticity is a learner's subjective interpretation of the veracity of a situation in which they interact with a context, other learners, and a simulator (Bland et al., 2014). For example, a high-fidelity simulation can be perceived as predictable (poor authenticity), whereas a low-fidelity simulation can be experienced as highly relevant to clinical practice (high authenticity). Proponents of situated and authentic learning argue that learning should be embedded in authentic activities and environments that reflect the way knowledge will be used in real life (Brown, Collins, \& Duguid, 1989; Herrington \& Oliver, 2000; Lave \& Wenger, 1991). They encourage the provision of authentic contexts that reflect the complexity and affordances of real-world activities, because cognition is inextricably linked to the situation in which it occurs. Another group of scholars, adopting a socio-technical or interactionist perspective, do not consider realism, fidelity, and authenticity as inherent characteristics of a simulation; they rather argue that these are emerging from the interaction between learners and the material world (Ahn \& Rimpilainen, 2018; Rystedt \& Sjoblom, 2012).

We propose that these conceptualizations can be grouped into three perspectives: 1) fidelity as a property of the simulation as operationalized by educators, 2) fidelity as experienced by learners (i.e., authenticity), and 3) fidelity as emerging from the interaction between learners and a simulation. However, beside the technology employed, practical features of simulation-based experiences that enhance fidelity — and situate the learner in an authentic representation of reality- 
remain nebulous (Bland et al., 2014). For an informed use of simulation, there is a need to clarify these features considering the complex social endeavor of simulation (Dieckmann et al., 2007). Based on the three perspectives proposed above, the purpose of the current review was to map features that promote fidelity and authenticity in simulation-based health professional educationbesides the type of simulator or technology employed.

\section{METHODS}

A scoping review based on the methodological framework proposed by Levac et al. (2010) was conducted and is reported according to the Preferred Reporting Items for Systematic Reviews and Meta-Analyses extension for scoping reviews (PRISMA-ScR) (Tricco et al., 2018). The aim of a scoping review is to summarize and interpret a broad range of evidence related to key concepts underpinning an area of research and can be used to clarify complex concepts. The protocol for this review was not prospectively registered or published.

\section{Inclusion criteria}

To determine eligibility criteria and define the search strategy, we used the PCC method (P: population, $\mathrm{C}$ : concept, $\mathrm{C}$ : context). In terms of population, this scoping review focused on students and licensed professionals from a variety of health-related disciplines, including but not limited to dentistry, medicine, midwifery, nursing, pharmacy, and rehabilitation. The concept of interest was simulation with a particular focus on facets of realism, fidelity, and authenticity. For the context, we focused on studies conducted in educational or clinical settings anywhere in the world.

Thus, to be included in this review, papers had to focus on realism, fidelity, and authenticity in simulation-based health professional education. Papers that did not include a substantive definition or discussion of realism, fidelity, or authenticity (i.e., more than one sentence) were excluded, as well as papers focusing on simulator technologies and engineering capabilities. For the type of sources, papers reporting research or evaluation studies published in English in peer-reviewed 
journals were considered. Grey literature was not considered because of the large number of empirical studies included in the review and the existence of numerous papers discussing the definition of realism, fidelity, and authenticity based on grey literature.

\section{Study search and selection}

The search strategy was developed by a medical librarian, using descriptors and keywords for the following concepts: realism, fidelity, authenticity, learning, and education in health sciences (Appendix 1). The databases used were CINAHL (EBSCO), ERIC (ProQuest), MEDLINE (Ovid), and Web of Science (Clarivate Analytics). Searches were conducted in July 2019, without time restriction. Of note, the search strategy was initially constructed to address health professional education and learning in general, without reference to a specific educational method. Since almost all retrieved papers discussed a form of simulation —including case studies, partial task-trainer, standardized patients, manikin-based simulation, and virtual simulation — we decided to narrow the scope of this review to simulation-based health professional education. The search strategy was not updated because it was already broad enough to retrieve references addressing simulation-based learning.

A first screening based on titles and abstracts was conducted by three independent reviewers (MFD, PL, RN). Then, in-depth reading of the papers was conducted independently by two reviewers (MFD, PL). Disagreements over the selection of papers were resolved through discussion and consensus. Reference were managed with EndNote X8 (ClarivateAnalytics).

\section{Data extraction}

The following information was extracted from the papers: country, methods and objectives, conceptual underpinnings, and results. Excerpts addressing the concepts of realism, fidelity, and authenticity were extracted by two reviewers (PL, MFD) using MAXQDA2018 (qualitative data analysis software, VERBI Gmbh), and then categorized according to the three perspectives 
proposed above: 1) operationalization by educators, 2) experience of learners, and 3) interactionist perspective. Excerpts were coded inductively (Miles, Huberman, \& Saldaña, 2014) to identify simulation features that contributed to fidelity and authenticity according to educators, learners, and from an interactionist perspective. Related codes were organized and synthesized into the features that are presented in the next section.

\section{RESULTS AND DISCUSSION}

We retrieved 6,595 unique references. After screening, a total of 42 papers were eligible for this review (see Figure 1). The studies (Table 1) used a variety of observational, evaluative, and experimental designs with students and professionals from various disciplines: nursing $(n=14)$, medicine $(n=13)$, interprofessional $(n=8)$, dentistry $(n=2)$, paramedicine $(n=2)$, environmental health $(n=1)$, midwifery $(n=1)$, operating department practitioners $(n=1)$. Based on the first author's affiliation, studies came from Europe $(n=20)$, North America $(n=12)$, Australia (n=6), and Asia $(n=4)$. Studies examined or compared several simulation formats, the most frequent being human patient simulators and computer-based simulations; standardized patients, partial task-trainers, and case studies were less represented.

Based on the three perspectives presented above, we identified practical features of fidelity and authenticity in health professional simulation-based learning. Seven features were described both from educators' and learners' perspectives: content drawn from real life, interaction and feedback, performance expectations, preparation of the environment, presence of an actual patient, logical and adaptive scenarios, and sociological fidelity. Features exclusively described as operationalized by educators, experienced by learners, and related to interactionist practices are reported in separated sections. Table 2 presents the number of papers describing features related to the three perspectives. It is important to note that the concepts of 'realism', 'fidelity', and 'authenticity' and 
were often used interchangeably in the papers. However, the following results are reported according to the definitions presented in Table 3 .

\section{Features both operationalized by educators and experienced by learners}

\section{Content drawn from real life}

This feature consisted in using real patient data or recreating events that occurred to actual patients. This could be achieved by using existing medical records or databases to define data to present to learners. For example, Ney, Goncalves, Blacheff, Schwartz, and Bosson (2010) provided students with access to a national database to evaluate the risk of thromboembolic diseases in an epidemiology game; Redmond et al. (2018) used data from real cases to develop digital learning activities for wound care education. Others reported recreating cases previously experienced by themselves or others (e.g., patients, professionals). Taylor (2011) described how standardized patients relied on their own experience or research others' experience to portray suffering. Furthermore, she explained that the fidelity of a scenario or performance can be assessed either by experienced professionals or by people living with the condition portrayed. Many studies reported that realistic scenarios or cases contributed to the fidelity or authenticity of simulation for learners (e.g., Goncalves, Croset, Ney, Balacheff, \& Bosson, 2010; MacLean, Geddes, Kelly, \& Della, 2019; Marei, Al-Eraky, Almasoud, Donkers, \& Van Merrienboer, 2018; Sørensen et al., 2015). On the contrary, some learners involved in the study by Sørensen et al. (2015) argued that it did not matter if cases were artificial.

Otherwise, the use of realistic images (e.g., photographs, radiographs) sometimes drawn from

previous cases — instead of more abstract representation (e.g., drawings)—was described as a means to improve fidelity, especially when virtual or digital media were involved. Comments from learners in a study by Falconer (2013) support that point. 


\section{Interaction and feedback}

Interaction was defined by the extent to which learners had the opportunity to engage with the patient and colleagues in a natural and dynamic manner in the simulation. To favor natural interactions, simulations involved opportunities for learners to talk freely (e.g., instead of choosing predefined sentences from a menu; Friedman, France, \& Drossman, 1991), real discussions constraints (e.g., not allowing the simulated patient to repeat information at learners' will; Goncalves et al., 2010), and real-time interaction with human beings to allow for a natural flow of conversation (e.g., Durning et al., 2012). In other cases, learners were required to use the same channels of communication as if the situation occurred in real-life (e.g., contacting the head of a department through email [Ney et al., 2010], or a dispatch center on a radio system [Engstrom et al., 2016]). The fact that they were observed interacting naturally with patients, either verbally or non-verbally (e.g., using therapeutic touch), was often mentioned as an indicator that they experienced the simulation as authentic (Ahn \& Rimpilainen, 2018; Dunn, Tyas, \& Garside, 2016; Engstrom et al., 2016; Falconer, 2013; Ignacio et al., 2015; Ker, Hesketh, Anderson, \& Johnston, 2006; Marei et al., 2018; Sørensen et al., 2015). Moreover, some learners commented that their interaction felt so authentic that they forgot that they were interacting with actors or a simulator (MacLean et al., 2019; Sørensen et al., 2015). Conversely, learners' perception that an interaction did not feel natural impeded their sense of authenticity. For example, Goncalves et al. (2010) explain how talking to an answering machine or getting a response by SMS was not perceived as credible.

Closely related to interaction is the type of feedback that learners receive during a simulation. We defined this feature as the opportunity for students to explore and witness the consequences of their actions in real-time, not after simulation (i.e., during debriefing). This imply that the situation unfolds in response to learners' actions — whether they are right or wrong — and does not follow a 
fixed course. In the sample, the form of feedback considered the most realistic often consisted of verbal reactions from the patient or changes in his or her condition (e.g., vital signs); text-based feedback or cues from educators was described as less realistic (see Dankbaar et al., 2016, for an example). While learners commented that they appreciated natural interactions with patient/colleagues, the papers reviewed did not include data on their experience of feedback.

\section{Performance expectations}

This feature was defined by the requirement to perform the actions that are expected in a simulation. Performance expectations can be divided into two subtypes: actual performance and time constraints. Actual performance requires learners to fully execute an action. A study by Engstrom et al. (2016) exemplifies this point: in the basic, low-realism condition, learners could simply inform the instructor that they would give a medication, whereas in the contextualized, high-realism condition, they had to actually prepare and deliver it. Dankbaar et al. (2016) described a partial performance expectation in an electronic module: learners did not have to fully perform an auscultation procedure in a computer simulation but were required to indicate the correct sites of auscultation in order to succeed. For learners, having to fully perform actions that they will perform in real life was perceived as contributing to the authenticity of the simulations (Falconer, 2013; Goncalves et al., 2010; Sadideen, Wilson, Moiemen, \& Kneebone, 2016); pretending to perform actions had the opposite impact (Ahn \& Rimpilainen, 2018; Engstrom et al., 2016).

The other type of performance expectation required events to occur in real-time or to last for as long as they would in real life. One way this feature was implemented was by imposing time pressures in a scenario that responded in real-time to learners' actions. In other cases, learners were required to perform actions for their true duration. For example, Krogh, Hoyer, Ostergaard, and Eika (2014) compared simulations in which learners had to perform cardiopulmonary resuscitation 
cycles of 120 seconds or 30-45 seconds, the former mirroring current guidelines. In a comparative study, Engstrom et al. (2016) exposed learners to two pre-hospital care simulations: in one, learners had to load the manikin in the ambulance and were directly transported to the hospital (jump in time and space); in the other, they drove for seven minutes to mirror actual transport time. From learners' perspective, training in real-time and experiencing time pressure and the need to prioritize were seen as increasing authenticity (McKittrick, Kinney, Lima, \& Allen, 2018; Ney et al., 2010; Sadideen, Wilson, Moiemen, \& Kneebone, 2014).

\section{Preparation of the environment}

This feature consisted in reproducing features of the environment where the situation could occur. Besides in situ simulation in Sorensen et al. (2015) and McKittrick et al. (2018)—as opposed to laboratory training - many authors (see Table 1) described how they used real props to simulate the environment (e.g., operating table, ambulance) and provided learners with real, functional equipment and devices (e.g., medication, monitors, phones, documentation). However, the lack of familiarity with the environment or an environment being too quiet compromised fidelity of the simulation for learners (Ker et al., 2006; Lee, Carson, Clarke, Yang, \& Nam, 2019; Mills et al., 2016).

Another tendency was to engage learners' senses. Simulating sounds that would occur in the work environment (e.g., monitor, surgical equipment) or environmental noises (e.g., dog barking, discussion between actors) was the most frequent features in that category (e.g., Engstrom et al., 2016; Marei et al., 2018; Mills et al., 2016). For learners, an environment perceived as too quiet diminished its authenticity (Mills et al., 2016). In other studies, odors (e.g., smell of tissue burned by an electrosurgical unit [Nanji et al., 2013]) and lighting (e.g., well-lit operating room, dark 
nightclub [Mills et al., 2016; Sadideen et al., 2014, 2016]) were simulated. Learners generally perceived these features as improving the authenticity of the simulations.

\section{Presence of patient}

Including an actual patient - either a manikin or a standardized patient - in the simulation environment was described as increasing fidelity. For example, Adams et al. (2015) compared a simulation with a monitor displaying vital signs — no patient was involved — and a simulation with a manikin in addition to the monitor. Brady, Bogossian, and Gibbons (2015) differentiated between levels of fidelity by providing students with a partial task-trainer, a partial task-trainer on top of an image of a patient, and a partial task-trainer positioned on a standardized patient, respectively. Learners generally appreciated the increased level of fidelity that the presence of the patient allowed (Mangold, 2016; Sadideen et al., 2014; Sørensen et al., 2015). Besides the fact that it allowed for more interaction and feedback, they perceived the psychomotor abilities of a real person - to manipulate material provided by a learner, for example - as enhancing the authenticity of their simulation experience (Mangold, 2016).

\section{Logical, adaptive scenario}

While it is expected that simulations unfold according to a scenario (INACSL Standards Committee, 2016), we identified three scenario characteristics that were deemed to improve simulation fidelity. First, higher-fidelity scenarios presented a logical sequence of events that required students to respond more or less urgently (Goncalves et al., 2010; Rystedt \& Sjoblom, 2012). Second, scenarios presenting options for learners to explore and evolving according to their own decisions were considered to be of higher fidelity than those who followed a fixed course (see Marei et al., 2018). Conversely, Hotchkiss, Biddle, and Fallacaro (2002) noted that learners' anticipation that something was about to go wrong no matter how they acted in the simulation 
compromised their sense of authenticity. Third, Mangold (2016) described how demographics of the simulated patient in the scenario were modified to match those of the actor portraying the role. Comments drawn from a study by Marei et al. (2018) revealed that students appreciated coherent storylines and uncertainty about correct decisions to implement in the scenarios.

\section{Sociological fidelity}

We identified diverse features that could be linked to the concept of sociological fidelity (Sharma et al., 2011). These features were defined as actions to increase learners' sense that they performed their real professional role, and the involvement of other protagonists in a simulation (beside the patient). Sadideen et al. $(2014,2016)$ described how various health professionals involved in a burn simulation were asked to perform their own professional role instead of switching to a different role (e.g., a nurse playing a respiratory therapist). Other authors added that learners were asked to wear their usual uniform or attire (Nanji, Baca, \& Raemer, 2013; Sadideen et al., 2014, 2016), or to use their personal phone or email application (Goncalves et al., 2010; Ney et al., 2010). Training in interprofessional teams was mentioned as a feature that enhanced fidelity, especially when the composition of teams reflected a credible mixture of professions and experience levels (McKittrick et al., 2018). Moreover, introducing protagonists beside the patient receiving care (e.g., patient's relatives or bystanders) increased learners' perception of authenticity (Mills et al., 2016; Sadideen et al., 2016). In general, these features were appreciated by learnersSørensen et al. (2015) even found that they were more important than the physical setting of the simulation. Oppositely, the presence of persons not involved in the scenario (i.e., observers) and the absence of characters from the scenario compromised learners' perception of authenticity (Ker et al., 2006; Mills et al., 2016), as well as failures to reproduce hierarchical relationships and unrealistic portrayal of certain professional roles (Hotchkiss et al., 2002). 


\section{Feature operationalized by educators}

We identified one feature that was solely described from educators' perspective: cueing. Cueing was defined as a method of providing learners with information during a simulation. Sometimes, cues were used to explain limitations and malfunctions of the simulator or the equipment, thereby compromising fidelity (Ahn \& Rimpilainen, 2018); Nanji et al. (2013) explained how presenting these limitations prior to a simulation and establishing a fiction contract could preserve fidelity. In other cases, cueing was used to provide learners with scenario information. According to some (Baptista et al., 2016; Brady et al., 2015; Meurling et al., 2014), using the manikin's features (e.g., voice or physical capabilities) or simulation equipment (e.g., patient monitor) was more realistic than having an instructor cue the information verbally (e.g., describing physiological values). Otherwise, Escher et al. (2017) identified four other methods of cueing, which had various impacts on learners' workflow and communication. The four methods consisted of providing cues with 1) a confederate involved in the scenario; 2) a bystander who did not partake in the scenario; 3) a loudspeaker; and 4) an earpiece worn by one of the learners.

\section{Features experienced by learners}

We identified three features that were solely described from learners' perspectives. First, learners behaving as if the situation was real and as they would in real life was described as a testimony of their sense of authenticity (Goncalves et al., 2010; Ker et al., 2006). Learners staying in character was perceived as a hallmark of authenticity, whereas interactions outside the scenario or breaches in learners' personification of their character (e.g., laughter, touching the manikin out of curiosity) were described as manifestations of poor authenticity (Engstrom et al., 2016; Goncalves et al., 2010; Rooney, Hopwood, Boud, \& Kelly, 2015; Rystedt \& Sjoblom, 2012). Second, Mills et al. (2016) reported that learners experiencing a sense of urgency to save the patient during the simulation, rather than being preoccupied with assessment, was another display of 
authenticity. Finally, Goncalves et al. (2010) claimed that learners feeling that they got too much help in the realization of a task (e.g., more feedback and resources than in the real world), or that they knew an outcome in advance (e.g., performing research analyses while knowing the results from a literature search) were two manifestations of poor authenticity.

\section{Features related to interactionist practices}

Authors adopting an interactionist perspective did not describe features of simulation but rather explained how learners and educators interacted with a simulation to maintain, breach, or reinstate its fidelity and learners' sense of authenticity. Five papers referring to an interactionist perspective described how fidelity and authenticity are constantly being enacted in learners' actions and reactions (Ahn \& Rimpilainen, 2018; Hindmarsh, Hyland, \& Banerjee, 2014; Rooney et al., 2015; Rystedt \& Sjoblom, 2012; Seale, Butler, Hutchby, Kinnersley, \& Rollnick, 2007). Breaches in fidelity could occur because of discrepancies with real practice, disruptions in usual work-flow patterns, performance of unexpected actions/non-performance of expected actions, and simulator malfunctions. These resulted in learners not enacting their professional role, treating the patient as a manikin and not as a patient, disregarding certain aspects of the scenario, and questioning the simulator's functionalities. Nevertheless, learners and educators performed actions to reinstate or promote fidelity and authenticity during simulations: displaying to each other how to understand the situation, framing tasks under real-life demands, invoking contingencies from the work setting, highlighting differences from real life (including limitations of the simulator), differentiating between aspects of the simulation relevant and irrelevant to real work, and providing excuses for discrepancies.

\section{Limitations}

The search strategy was limited to peer-reviewed journals indexed in certain databases and did not include keywords related to simulation-based education. Contrarily to recommendations for 
scoping reviews, grey literature as well as dissertations and theses were not considered. We did not appraise the quality of the evidence of the studies, and there were major methodological variations in the sample. Therefore, our results should not be considered as evidence of effectiveness. Finally, we only considered features that were explicitly associated with realism, fidelity, and authenticity in the papers. For example, papers that mentioned using real radiographs but did not clearly associated this feature with realism, fidelity, or authenticity were not included in this review. Thus, it is possible that relevant studies were excluded.

\section{CONCLUSION}

In this scoping review, we identified eight practical features that can be operationalized by educators to promote fidelity or authenticity in simulation-based education: content drawn from real life, interaction and feedback, performance expectations, preparation of the environment, presence of an actual patient, logical and adaptive scenarios, sociological fidelity, and cueing. Moreover, we identified manifestations of learners' experience of authenticity, as well as interactionist practices that led to enactment of fidelity and authenticity. The features presented above are coherent with current definitions presented in the Healthcare Simulation Dictionary (Lopreiato, 2016) and endorsed by the International Association for Clinical Simulation and Learning (INACSL Standards Committee, 2016). While these features are a powerful analytic tool to enhance our understanding of the concepts of fidelity, authenticity, and realism, they can act as an instructional framework to assist the design of high-fidelity, authentic simulations, even when technology is scarce or unavailable. 


\section{ACKNOWLEDGMENTS}

This work was supported by Équipe FUTUR, which is funded by the Fonds de recherche du Québec - Société et culture (FRQ-SC). The authors would like to acknowledge the participation of Assia Mourid, B. Sc., M. S. I, who helped develop the search strateg y for this review. 


\section{REFERENCES}

Adams, A. J., Wasson, E. A., Admire, J. R., Pablo Gomez, P., Babayeuski, R. A., Sako, E. Y., \& Willis, R. E. (2015). A comparison of teaching modalities and fidelity of simulation levels in teaching resuscitation scenarios. Journal of Surgical Education, 72(5), 778-785. https://dx.doi.org/10.1016/j.jsurg.2015.04.011

Ahn, S. E. \& Rimpilainen, S. (2018). Maintaining Sofia - or how to reach the intended learning outcomes during a medical simulation training. International Journal of Learning Technology, 13(2), 115-129. https://dx.doi.org/10.1504/ijlt.2018.092095

Alessi, S. M. (1988). Fidelity in the design of instructional simulations. Journal of Computer-Based Instruction, 15(2), 40-47.

Allen, J., Buffardi, L., \& Hays, R. (1991). The relationship of simulator fidelity to task and performance variables (Report no. ARI-91-58). Alexandria, VA : United States Army Research Institute for the Behavioral and Social Sciences. Retrieved from https://apps.dtic.mil/dtic/tr/fulltext/u2/a238941.pdf

Baptista, R. C., Paiva, L. A., Gonçalves, R. F., Oliveira, L. M., Pereira, M. F., \& Martins, J. C. (2016). Satisfaction and gains perceived by nursing students with medium and high-fidelity simulation: A randomized controlled trial. Nurse Education Today, 46(November), $127-$ 132. https://doi.org/10.1016/j.nedt.2016.08.027

Barrows, H. S. \& Tamblyn, R. M. (1980). Problem-based learning: An approach to medical education. New York, NY: Springer.

Baxter, P., Akhtar-Danesh, N., Valaitis, R., Stanyon, W., \& Sproul, S. (2009). Simulated experiences: Nursing students share their perspectives. Nurse Education Today, 29(8), 859866. https://doi.org/10.1016/j.nedt.2009.05.003

Beaubien, J. M. \& Baker, D. P. (2004). The use of simulation for training teamwork skills in health care: How low can you go? Quality \& Safety in Health Care, 13(suppl. 1), I51-I56. https://doi.org/10.1136/qshc.2004.009845

Beaumont, C., Savin-Baden, M., Conradi, E., \& Poulton, T. (2014). Evaluating a "Second Life" problem-based learning (PBL) demonstrator project: What can we learn? Interactive Learning Environments, 22(1), 125-141. doi: https://dx.doi.org/10.1080/10494820.2011.641681

Bland, A. J., Topping, A., \& Tobbell, J. (2014). Time to unravel the conceptual confusion of authenticity and fidelity and their contribution to learning within simulation-based nurse education. A discussion paper. Nurse Education Today, 34(7), 1112-1118. https://doi.org/10.1016/j.nedt.2014.03.009

Bonito, S. R. (2019). The usefulness of case studies in a Virtual Clinical Environment (VCE) multimedia courseware in nursing. Journal of Medical Investigation, 66(1-2), 38-41. https://doi.org/10.2152/jmi.66.38 
Brackney, D. E. \& Priode, K. (2017). Back to reality: The use of the presence questionnaire for measurement of fidelity in simulation. Journal of Nursing Measurement, 25(2), E66-E73. https://doi.org/10.1891/1061-3749.25.2.E66

Brady, S., Bogossian, F., \& Gibbons, K. (2015). The effectiveness of varied levels of simulation fidelity on integrated performance of technical skills in midwifery students: A randomised intervention trial. Nurse Education Today, 35(3), 524-529. https://doi.org/10.1016/j.nedt.2014.11.005

Brown, J. S., Collins, A., \& Duguid, P. (1989). Situated cognition and the culture of learning. Educational Researcher, 18(1), 32-42. https://doi.org/10.3102/0013189X018001032

Brydges, R., Carnahan, H., Rose, D., \& Dubrowski, A. (2010). Comparing self-guided learning and educator-guided learning formats for simulation-based clinical training. Journal of Advanced Nursing, 66(8), 1832-1844. https://doi.org/10.1111/j.1365-2648.2010.05338.x

Brydges, R., Carnahan, H., Rose, D., Rose, L., \& Dubrowski, A. (2010). Coordinating progressive levels of simulation fidelity to maximize educational benefit. Academic Medicine, 85(5), 806-812. https://doi.org/10.1097/ACM.0b013e3181d7aabd

Dankbaar, M. E. W., Alsma, J., Jansen, E. E. H., van Merrienboer, J. J. G., van Saase, J. L. C. M., \& Schuit, S. C. E. (2016). An experimental study on the effects of a simulation game on students' clinical cognitive skills and motivation. Advances in Health Sciences Education, 21(3), 505-521. https://doi.org/10.1007/s10459-015-9641-x

Dickinson, B. L., Lackey, W., Sheakley, M., Miller, L., Jevert, S., \& Shattuck, B. (2018). Involving a real patient in the design and implementation of case-based learning to engage learners. Advances in Physiology Education, 42(1), 118-122. https://doi.org/10.1152/advan.00174.2017

Dieckmann, P., Gaba, D., \& Rall, M. (2007). Deepening the theoretical foundations of patient simulation as social practice. Simulation in Healthcare, 2(3), 183-193. https://dx.doi.org/10.1097/SIH.0b013e3180f637f5

Dunn, L., Tyas, M., \& Garside, J. (2016). Preregistration students' reactions to simulation as an education approach within an operating department practitioner curriculum: A qualitative review. Clinical Simulation in Nursing, 12(5), 147-151. https://doi.org/10.1016/j.ecns.2015.12.012

Durning, S. J. \& Artino, A. R. (2011). Situativity theory: A perspective on how participants and the environment can interact: AMEE Guide no. 52. Medical Teacher, 33(3), 188-199. https://doi.org/10.3109/0142159X.2011.550965

Durning, S. J., Dong, T., Artino, A. R., Jr., LaRochelle, J., Pangaro, L. N., van der Vleuten, C., . . Schuwirth, L. (2012). Instructional authenticity and clinical reasoning in undergraduate medical education: A 2-year, prospective, randomized trial. Military Medicine, 177(suppl. 9), 38-43. https://doi.org/10.7205/milmed-d-12-00234 
Engstrom, H., Andersson Hagiwara, M., Backlund, P., Lebram, M., Lundberg, L., Johannesson, M., . . . Maurin Soderholm, H. (2016). The impact of contextualization on immersion in healthcare simulation. Advances in Simulation, 1, article 8. doi: https://doi.org/10.1186/s41077-016-0009-y

Escher, C., Rystedt, H., Creutzfeldt, J., Meurling, L., Nystrom, S., Dahlberg, J., . . . AbrandtDahlgren, M. (2017). Method matters: Impact of in-scenario instruction on simulationbased teamwork training. Advances in Simulation, 2, article 25. doi: https://doi.org/10.1186/s41077-017-0059-9

Falconer, L. (2013). Situated learning in virtual simulations: Researching the authentic dimension in virtual worlds. Journal of Interactive Learning Research, 24(3), 285-300. Retrieved from https://www.learntechlib.org/p/40484/

Fenwick, T. J. \& Nerland, M. (2014). Reconceptualising professional learning: Sociomaterial knowledges, practices and responsibilities. New York, NY: Routledge.

Friedman, C. P., France, C. L., \& Drossman, D. D. (1991). A randomized comparison of alternative formats for clinical simulations. Medical Decision Making, 11(4), 265-272. https://doi.org/10.1177/0272989x9101100404

Gaba, D. M. (2004). The future vision of simulation in health care. Quality and Safety in Health Care, 13(suppl. 1), i2-i10. https://doi.org/10.1136/qshc.2004.009878

Gonçalves, C., Croset, M. C., Ney, M., Balacheff, N., \& Bosson, J. L. (2010). Authenticity in learning game: How it is designed and perceived. In M. Wolpers, P. A. Kirschner, M. Scheffel, S. Lindstaedt \& V. Dimitrova (eds.), Sustaining Tel: From Innovation to Learning and Practice. EC-TEL 2010. Lectures Notes in Computer Science (Vol. 6383, p. 109-122). Berlin: Springer. https://doi.org/10.1007/978-3-642-16020-2_8

Grierson, L. E. M. (2014). Information processing, specificity of practice, and the transfer of learning: Considerations for reconsidering fidelity. Advances in Health Sciences Education, 19(2), 281-289. https://doi.org/10.1007/s10459-014-9504-x

Gulikers, J. T. M., Basiaens, T. J., Martens, R. L. (2005). The surplus value of an authentic learning environment. Computers in Human Behaviors, 21(3), 509-521. https://doi.org/10.1016/j.chb.2004.10.028

Hamstra, S. J., Brydges, R., Hatala, R., Zendejas, B., \& Cook, D. A. (2014). Reconsidering fidelity in simulation-based training. Academic Medicine, 89(3), 387-392. https://doi.org/10.1097/acm.0000000000000130

Herrington, J. \& Oliver, R. (2000). An instructional design framework for authentic learning environments. Educational Technology Research and Development, 48(3), 23-48. https://doi.org/10.1007/BF02319856 
Hindmarsh, J., Hyland, L., \& Banerjee, A. (2014). Work to make simulation work: 'Realism', instructional correction and the body in training. Discourse Studies, 16(2), 247-269. https://doi.org/10.1177/1461445613514670

Hotchkiss, M. A., Biddle, C., \& Fallacaro, M. (2002). Assessing the authenticity of the human simulation experience in anesthesiology. AANA Journal, 70(6), 470-473. Retrieved from https://www.aana.com/docs/default-source/aana-journal-web-documents-1/470473.pdf?sfvrsn=53c755b1_6

Ignacio, J., Dolmans, D., Scherpbier, A., Rethans, J.-J., Chan, S., \& Liaw, S. Y. (2015). Comparison of standardized patients with high-fidelity simulators for managing stress and improving performance in clinical deterioration: A mixed methods study. Nurse Education Today, 35(12), 1161-1168. https://doi.org/10.1016/j.nedt.2015.05.009

INACSL Standards Committee. (2016). INACSL Standards of best practice: Simulation ${ }^{\text {SM. }}$ Simulation design. Clinical Simulation In Nursing, 12(suppl.), S39-S47. https://doi.org/10.1016/j.ecns.2016.09.012

Ker, J. S., Hesketh, E. A., Anderson, F., \& Johnston, D. A. (2006). Can a ward simulation exercise achieve the realism that reflects the complexity of everyday practice junior doctors encounter? Medical Teacher, 28(4), 330-334. doi: https://doi.org/10.1080/01421590600627623

Knobloch, N. A. (2003). Is experiential learning authentic? Journal of Agricultural Education, 44(4), 22-34. https://doi.org/10.5032/jae.2003.04022

Knowles, M. (1984). Andragogy in action: Applying modern principles of adult education. San Francisco, CA: Jossey Bass.

Krogh, K. B., Hoyer, C. B., Ostergaard, D., \& Eika, B. (2014). Time matters: Realism in $\begin{array}{llll}\text { resuscitation } \quad \text { training. } & \text { Resuscitation, }\end{array}$ https://doi.org/10.1016/j.resuscitation.2014.05.008

Lave, J. \& Wenger, E. (1991). Situated learning: Legitimate peripheral participation. Cambridge: Cambridge University Press.

Lee, J. J., Carson, M. N., Clarke, C. L., Yang, S. C., \& Nam, S. J. (2019). Nursing students' learning dynamics with clinical information and communication technology: A constructive grounded theory approach. Nurse Education Today, 73(February), 41-47. https://doi.org/10.1016/j.nedt.2018.11.007

Levac, D., Colquhoun, H., \& O'Brien, K. K. (2010). Scoping studies: Advancing the methodology. Implementation Science, 5, article 69. https://doi.org/10.1186/1748-5908-5-69

Lopreiato, J. O. (2016). Healthcare Simulation Dictionary. Rockville, MD: Agency for Healthcare Research and Quality. AHRQ Publication No. 16(17)-0043. https://www.ahrq.gov/sites/default/files/publications/files/sim-dictionary.pdf 
MacLean, S., Geddes, F., Kelly, M., \& Della, P. (2019). Realism and presence in simulation: Nursing student perceptions and learning outcomes. Journal of Nursing Education, 58(6), 330-338. https://doi.org/10.3928/01484834-20190521-03

Mangold, K. (2016). Utilization of the simulation environment to practice teach-back with kidney transplant patients. Clinical Simulation in Nursing, 12(12), 532-538. https://doi.org/10.1016/j.ecns.2016.08.004

Maran, N. J. \& Glavin, R. J. (2003). Low- to high-fidelity simulation: A continuum of medical education? Medical Education, 37(s1), 22-28. https://doi.org/10.1046/j.13652923.37.s1.9.x

Marei, H. F., Al-Eraky, M. M., Almasoud, N. N., Donkers, J., \& Van Merriënboer, J. J. G. (2018). The use of virtual patient scenarios as a vehicle for teaching professionalism. European Journal of Dental Education, 22(2), E253-E260. https://doi.org/10.1111/eje.12283

McKittrick, J. T., Kinney, S., Lima, S., \& Allen, M. (2018). The first 3 minutes: Optimising a short realistic paediatric team resuscitation training session. Nurse Education in Practice, 28(January), 115-120. https://doi.org/10.1016/j.nepr.2017.10.020

Meurling, L., Hedman, L., Lidefelt, K. J., Escher, C., Fellander-Tsai, L., \& Wallin, C. J. (2014). Comparison of high- and low equipment fidelity during paediatric simulation team training: a case control study. BMC Medical Education, 14, article 221. https://doi.org/10.1186/1472-6920-14-221

Miles, M. B., Huberman, M., \& Saldaña, J. (2014). Qualitative data analysis: A methods sourcebook. (3rd ed.). Los Angeles, CA: Sage.

Miller, R. B. (1954). Psychological considerations in the design of training equipment (Report no. WADC-TR54-563). Wright-Patterson Air Force Base, OH: American Institute for Research. http://contrails.iit.edu/reports/2508

Mills, B. W., Carter, O. B., Rudd, C. J., Claxton, L. A., Ross, N. P., \& Strobel, N. A. (2016). Effects of low- versus high-fidelity simulations on the cognitive burden and performance of entrylevel paramedicine students: A mixed-methods comparison trial using eye-tracking, continuous heart rate, difficulty rating scales, video observation and interviews. Simulation in Healthcare, 11(1), 10-18. https://doi.org/10.1097/SIH.0000000000000119

Nanji, K. C., Baca, K., \& Raemer, D. B. (2013). The effect of an olfactory and visual cue on realism and engagement in a health care simulation experience. Simulation in Healthcare, 8(3), 143-147. https://doi.org/10.1097/SIH.0b013e31827d27f9

Ney, M., Goncalves, C., Blacheff, N., Schwartz, C., \& Bosson, J. L. (2010). Phone, email and video interactions with characters in an epidemiology game: Towards authenticity. In Z. G. Pan, A. D. Cheok, W. Muller, X. P. Zhang \& K. Wong (dir.), Transactions on Edutainment IV. Lecture Notes in Computer Science (Vol. 6250, p. 241-255). Berlin: Springer. https://doi.org/10.1007/978-3-642-14484-4_20 
Norman, G., Dore, K., \& Grierson, L. (2012). The minimal relationship between simulation fidelity and transfer of learning. Medical Education, 46(7), 636-647. https://doi.org/10.1111/j.1365-2923.2012.04243.x

Paas, F., Renkl, A., \& Sweller, J. (2003). Cognitive load theory and instructional design: Recent developments. $\quad$ Educational $\quad$ Psychologist, $\quad 38(1), \quad 1-4$. https://doi.org/10.1207/s15326985ep3801 1

Paige, J. B. \& Morin, K. H. (2013). Simulation fidelity and cueing: A systematic review of the literature. Clinical Simulation in Nursing, 9(11), E481-E489. https://doi.org/10.1016/j.ecns.2013.01.001

Redmond, C., Davies, C., Cornally, D., Adam, E., Daly, O., Fegan, M., \& O'Toole, M. (2018). Using reusable learning objects (RLOs) in wound care education: Undergraduate student nurse's evaluation of their learning gain. Nurse Education Today, 60(January), 3-10. https://doi.org/10.1016/j.nedt.2017.09.014

Rehmann, A. J., Mitman, R. D., \& Reynolds, M. C. (1995). A handbook of flight simulation fidelity requirements for human factors research (Report no. CT-TN95/46). Atlantic City Internation Airport, NJ: U.S. Department of Transportation, Federal Aviation Center. Retrieved from https://apps.dtic.mil/dtic/tr/fulltext/u2/a303799.pdf

Rooney, D., Hopwood, N., Boud, D., \& Kelly, M. (2015). The role of simulation in pedagogies of higher education for the health professions: Through a practice-based lens. Vocations and Learning, 8(3), 269-285. https://doi.org/10.1007/s12186-015-9138-z

Rystedt, H. \& Sjoblom, B. (2012). Realism, authenticity, and learning in healthcare simulations: Rules of relevance and irrelevance as interactive achievements. Instructional Science, 40(5), 785-798. doi: https://doi.org/10.1007/s11251-012-9213-x

Sadideen, H., Wilson, D., Moiemen, N., \& Kneebone, R. (2014). Proposing "The Burns Suite" as a novel simulation tool for advancing the delivery of burns education. Journal of Burn Care \& Research, 35(1), 62-71. https://doi.org/10.1097/BCR.0b013e31829b371d

Sadideen, H., Wilson, D., Moiemen, N., \& Kneebone, R. (2016). Using "The Burns Suite" as a novel high fidelity simulation tool for interprofessional and teamwork training. Journal of Burn Care \& Research, 37(4), 235-242. https://doi.org/10.1097/BCR.0000000000000262

Seale, C., Butler, C. C., Hutchby, I., Kinnersley, P., \& Rollnick, S. (2007). Negotiating frame ambiguity: A study of simulated encounters in medical education. Communication \& Medicine, 4(2), 177-187. https://doi.org/10.1515/CAM.2007.021

Sharma, S., Boet, S., Kitto, S., \& Reeves, S. (2011). Interprofessional simulated learning: The need for "sociological fidelity". Journal of Interprofessional Care, 25(2), 81-83. https://doi.org/10.3109/13561820.2011.556514

Sherwood, R. J. \& Francis, G. (2018). The effect of mannequin fidelity on the achievement of learning outcomes for nursing, midwifery and allied healthcare practitioners: Systematic 
review and meta-analysis. Nurse Education Today, 69(Octobre), 81-94. https://doi.org/10.1016/j.nedt.2018.06.025

Sørensen, J. L., Navne, L. E., Martin, H. M., Ottesen, B., Albrecthsen, C. K., Pedersen, B. W., . . . van der Vleuten, C. (2015). Clarifying the learning experiences of healthcare professionals with in situ and off-site simulation-based medical education: A qualitative study. $B M J$ Open, 5(10), e008345. https://doi.org/10.1136/bmjopen-2015-008345

Stillman, G., Alison, J., Croker, F., Tonkin, C., \& White, B. (1998). Situated learning as a model for the design of an interactive multimedia program on medication administration for nurses. Innovations in Education and Training International, 35(4), 329-336. https://doi.org/10.1080/1355800980350408

Sweller, J. (1988). Cognitive load during problem solving: Effects on learning. Cognitive Science, 12(2), 257-285. https://doi.org/10.1016/0364-0213(88)90023-7

Taylor, J. S. (2011). The moral aesthetics of simulated suffering in standardized patient performances. Culture Medicine and Psychiatry, 35(2), 134-162. https://doi.org/10.1007/s11013-011-9211-5

Tricco, A. C., Lillie, E., Zarin, W., O'Brien, K. K., Colquhoun, H., Levac, D., . . Straus, S. E. (2018). PRISMA Extension for scoping reviews (PRISMA-ScR): Checklist and explanation. Annals of Internal Medicine, 169(7), 467-473. https://doi.org/10.7326/m18$\underline{0850}$

Tun, J. K., Alinier, G., Tang, J., \& Kneebone, R. L. (2015). Redefining simulation fidelity for healthcare education. Simulation \& Gaming, 46(2), 159-174. https://doi.org/10.1177/1046878115576103

Van Merriënboer, J. J. \& Sweller, J. (2010). Cognitive load theory in health professional education: Design principles and strategies. Medical Education, 44(1), 85-93. https://doi.org/10.1111/j.1365-2923.2009.03498.x

West, A. J., Beaumie, K., \& Parchoma, G. (2017). Towards an enhanced conceptualization of fidelity for instructional design in simulation-based respiratory therapy education. Canadian Journal of Respiratory Therapy, 53(4), 69-74. Retrieved from https://www.cjrt.ca/wp-content/uploads/Towards-an-enhanced-conceptualization-offidelity.pdf

Yoo, J.-H. \& Kim, Y.-J. (2018). Factors influencing nursing students' flow experience during simulation-based learning. Clinical Simulation in Nursing, 24(November), 1-8. https://doi.org/10.1016/j.ecns.2018.09.001 
Table 1. Studies included in the scoping review

\begin{tabular}{|c|c|c|c|c|c|}
\hline & $\begin{array}{l}\text { Reference } \\
\text { Country }\end{array}$ & Methods and objective(s) & Conceptual underpinning & Features & $\begin{array}{l}\text { Relevant results and } \\
\text { recommendations }\end{array}$ \\
\hline 1. & $\begin{array}{l}\text { Adams et al. } \\
(2015) \\
\text { USA }\end{array}$ & $\begin{array}{l}\text { Randomized control trial (RCT) } \\
\text { To compare } 4 \text { teaching modalities } \\
\text { (lectures, videos, low-fidelity } \\
\text { (computer-based) and HPS } \\
\text { simulation) and fidelity of } \\
\text { simulation levels in teaching } \\
\text { resuscitation scenario }\end{array}$ & $\begin{array}{l}\text { Engineering and } \\
\text { psychological fidelity } \\
\text { (Miller, 1954) } \\
\text { Cognitive load theory with } \\
\text { respect to the number of } \\
\text { stimuli in high-fidelity } \\
\text { simulation (Alessi, 1988; } \\
\text { Sweller, 1988) }\end{array}$ & $\begin{array}{l}\text { Preparation of environment } \\
\text { Presence of patient } \\
\text { Sociological fidelity }\end{array}$ & $\begin{array}{l}\text { Video- and simulation-based } \\
\text { training was associated with better } \\
\text { learning outcomes compared to } \\
\text { lectures only. } \\
\text { Video-based, low and high-fidelity } \\
\text { yielded similar outcomes. }\end{array}$ \\
\hline 2. & $\begin{array}{l}\text { Ahn and } \\
\text { Rimpilainen } \\
\text { (2018) } \\
\text { Scotland }\end{array}$ & $\begin{array}{l}\text { Qualitative } \\
\text { To observe HPS trauma simulation } \\
\text { to understand what makes a } \\
\text { successful simulation (intended } \\
\text { learning path and outcomes) }\end{array}$ & $\begin{array}{l}\text { Interactionist perspective: } \\
\text { Fidelity emerges from the } \\
\text { interplay of the manikin, } \\
\text { scenario, and technology, } \\
\text { and the active engagement } \\
\text { of participants } \\
\text { Actor-network theory } \\
\text { (Fenwick \& Nerland, 2014) }\end{array}$ & $\begin{array}{l}\text { Interaction and feedback } \\
\text { Performance expectations } \\
\text { Cueing } \\
\text { Interactionist practices }\end{array}$ & $\begin{array}{l}\text { Briefing frames what actions are } \\
\text { possible and impossible in the } \\
\text { simulation, which in turn defines } \\
\text { actions that are appropriate and } \\
\text { inappropriate. } \\
\text { Simulations are emergent and co- } \\
\text { constituted by socio-material actors. }\end{array}$ \\
\hline 3. & $\begin{array}{l}\text { Baptista et al. } \\
\text { (2016) } \\
\text { Portugal }\end{array}$ & $\begin{array}{l}\text { RCT } \\
\text { To compare satisfaction and gains } \\
\text { perceived in medium and HPS } \\
\text { simulation }\end{array}$ & $\begin{array}{l}\text { Patient, clinical, and health } \\
\text { facility dimensions of } \\
\text { fidelity (Tun et al., 2015) } \\
\text { Psychological fidelity }\end{array}$ & $\begin{array}{l}\text { Preparation of environment } \\
\text { Cueing }\end{array}$ & $\begin{array}{l}\text { HPS led to higher perception of } \\
\text { realism, satisfaction, and perceived } \\
\text { gains. }\end{array}$ \\
\hline 4. & $\begin{array}{l}\text { Beaumont, } \\
\text { Savin-Baden, } \\
\text { Conradi, and } \\
\text { Poulton (2014) } \\
\text { United Kingdom }\end{array}$ & $\begin{array}{l}\text { Qualitative evaluation study } \\
\text { To develop, deliver and test eight } \\
\text { PBL scenarios in a 3D virtual world }\end{array}$ & $\begin{array}{l}\text { Authentic PBL (Barrows \& } \\
\text { Tamblyn, 1980) }\end{array}$ & $\begin{array}{l}\text { Content drawn from real life } \\
\text { Interaction and feedback } \\
\text { Presence of patient } \\
\text { Logical, adaptive scenario }\end{array}$ & $\begin{array}{l}\text { Virtual world provided a rich, } \\
\text { engaging environment, which } \\
\text { enhanced authenticity of the } \\
\text { scenarios. }\end{array}$ \\
\hline 5. & $\begin{array}{l}\text { Bonito (2019) } \\
\text { Philippines }\end{array}$ & $\begin{array}{l}\text { Descriptive evaluation study } \\
\text { To describe the usefulness of a } \\
\text { multimedia case study for learning }\end{array}$ & $\begin{array}{l}\text { Authentic learning } \\
\text { (Herrington \& Oliver, } \\
\text { 2000) }\end{array}$ & $\begin{array}{l}\text { Content drawn from real life } \\
\text { Logical, adaptive scenario }\end{array}$ & $\begin{array}{l}\text { Students describe the cases as } \\
\text { similar to actual cases seen in } \\
\text { hospitals and scenarios as realistic. }\end{array}$ \\
\hline 6. & $\begin{array}{l}\text { Brackney and } \\
\text { Priode (2017) } \\
\text { USA }\end{array}$ & $\begin{array}{l}\text { Correlational study } \\
\text { To examine students' perception of } \\
\text { realism in a simulation and to report } \\
\text { the strengths and limitations of the } \\
\text { Presence Questionnaire in HPS } \\
\text { simulations }\end{array}$ & $\begin{array}{l}\text { Physical, conceptual, and } \\
\text { psychological fidelity } \\
\text { (INACSL Standards } \\
\text { Committee, 2016) }\end{array}$ & $\begin{array}{l}\text { Interaction and feedback } \\
\text { Preparation of environment }\end{array}$ & $\begin{array}{l}\text { The realism subscale of the } \\
\text { Presence Questionnaire is a valid } \\
\text { measure of simulation fidelity. }\end{array}$ \\
\hline
\end{tabular}




\begin{tabular}{|c|c|c|c|c|c|}
\hline 7. & $\begin{array}{l}\text { Brady et al. } \\
(2015) \\
\text { Australia }\end{array}$ & $\begin{array}{l}\text { RCT } \\
\text { To evaluate the effectiveness of } \\
\text { varying levels of fidelity (PTT, PTT } \\
\text { on poster, PTT and SP) on learning } \\
\text { experiences and clinical skills } \\
\text { development }\end{array}$ & $\begin{array}{l}\text { Environmental and } \\
\text { psychological fidelity }\end{array}$ & $\begin{array}{l}\text { Presence of patient } \\
\text { Cueing }\end{array}$ & $\begin{array}{l}\text { Progressive and medium-fidelity } \\
\text { yielded better outcomes that low- } \\
\text { fidelity. }\end{array}$ \\
\hline 8. & $\begin{array}{l}\text { Brydges, } \\
\text { Carnahan, Rose, } \\
\text { and Dubrowski } \\
(2010) \\
\text { Canada }\end{array}$ & $\begin{array}{l}\text { RCT } \\
\text { To compare self-guided learning } \\
\text { and educator-guided learning } \\
\text { formats for simulation-based } \\
\text { clinical training }\end{array}$ & $\begin{array}{l}\text { Fidelity as students' } \\
\text { perceived sense of realism, } \\
\text { and how realistically the } \\
\text { simulator responds to their } \\
\text { actions (Alessi, 1988) }\end{array}$ & $\begin{array}{l}\text { Preparation of environment } \\
\text { Cueing }\end{array}$ & $\begin{array}{l}\text { Progressive and proficiency-based } \\
\text { training yielded similar learning } \\
\text { outcomes, suggesting that students } \\
\text { knew when to switch between } \\
\text { simulators. Students preferred } \\
\text { progressive training. }\end{array}$ \\
\hline 9. & $\begin{array}{l}\text { Brydges, } \\
\text { Carnahan, Rose, } \\
\text { Rose, and } \\
\text { Dubrowski } \\
\text { (2010) } \\
\text { Canada }\end{array}$ & $\begin{array}{l}\text { RCT } \\
\text { To test the efficacy and feasibility } \\
\text { of progressive learning on low- } \\
\text { fidelity (computer simulation), mid- } \\
\text { fidelity (PTT) and HPS simulation } \\
\text { compared with the use of } \\
\text { simulators in isolation }\end{array}$ & $\begin{array}{l}\text { Fidelity as realism (Alessi, } \\
\text { 1988) }\end{array}$ & $\begin{array}{l}\text { Preparation of environment } \\
\text { Cueing }\end{array}$ & $\begin{array}{l}\text { HPS group had better learning } \\
\text { outcomes than low-fidelity group. } \\
\text { Progressive group scored higher on } \\
\text { documentation and clinical } \\
\text { performance, and equivalent on } \\
\text { other outcomes. Progressive fidelity } \\
\text { was resource efficient. }\end{array}$ \\
\hline 10. & $\begin{array}{l}\text { Dankbaar et al. } \\
\text { (2016) } \\
\text { The Netherlands }\end{array}$ & $\begin{array}{l}\text { RCT } \\
\text { To investigate the effects of e- } \\
\text { module only, e-module with low- } \\
\text { fidelity text-based cases, and e- } \\
\text { module with high-fidelity } \\
\text { simulation game (computer } \\
\text { simulation) on students' skills, } \\
\text { engagement, and motivation }\end{array}$ & $\begin{array}{l}\text { Fidelity as a function of the } \\
\text { learning task, the learners, } \\
\text { and the context (Hamstra et } \\
\text { al., 2014); } \\
\text { Physical, psychological, } \\
\text { functional fidelity } \\
\text { Cognitive load theory } \\
\text { (Paas, Renkl, \& Sweller, } \\
\text { 2003) }\end{array}$ & $\begin{array}{l}\text { Interaction and feedback } \\
\text { Performance expectations } \\
\text { Preparation of environment } \\
\text { Logical, adaptive scenario }\end{array}$ & $\begin{array}{l}\text { Learning time was shorter for the e- } \\
\text { module only group. No difference } \\
\text { between groups in cognitive skills } \\
\text { acquired. } \\
\text { The game group experienced more } \\
\text { cognitive load and engagement than } \\
\text { the cases group. }\end{array}$ \\
\hline 11. & $\begin{array}{l}\text { Dickinson et al. } \\
\text { (2018) } \\
\text { USA }\end{array}$ & $\begin{array}{l}\text { Descriptive evaluation study } \\
\text { To assess students' perception of a } \\
\text { case-based learning intervention } \\
\text { involving a real patient }\end{array}$ & $\begin{array}{l}\text { Authenticity for learning } \\
\text { (Knowles, 1984) }\end{array}$ & $\begin{array}{l}\text { Content drawn from real life } \\
\text { Interaction and feedback } \\
\text { Presence of patient }\end{array}$ & $\begin{array}{l}\text { Students agreed that the activity } \\
\text { provided an authentic learning } \\
\text { experience, helped to apply science } \\
\text { concepts to a case, and increased } \\
\text { their engagement. }\end{array}$ \\
\hline 12. & $\begin{array}{l}\text { Dunn et al. } \\
\text { (2016) } \\
\text { United Kingdom }\end{array}$ & $\begin{array}{l}\text { Qualitative (Phenomenological) } \\
\text { To understand students' } \\
\text { perspectives and experiences of } \\
\text { HPS simulation as a learning and } \\
\text { assessment strategy }\end{array}$ & $\begin{array}{l}\text { Engineering and } \\
\text { psychological fidelity } \\
\text { (Baxter, Akhtar-Danesh, } \\
\text { Valaitis, Stanyon, \& Sproul, } \\
\text { 2009) }\end{array}$ & Interaction and feedback & $\begin{array}{l}\text { Interaction using the manikin's } \\
\text { voice improved students' } \\
\text { experience. }\end{array}$ \\
\hline
\end{tabular}




\begin{tabular}{|c|c|c|c|c|c|}
\hline 13. & $\begin{array}{l}\text { Durning et al. } \\
(2012) \\
\text { USA }\end{array}$ & $\begin{array}{l}\text { Crossover RCT } \\
\text { To test the effect of instructional } \\
\text { format (paper case, video, live } \\
\text { recreation with SP) on students' } \\
\text { clinical reasoning outcomes }\end{array}$ & $\begin{array}{l}\text { Authenticity as the } \\
\text { proximity of instructional } \\
\text { format with actual practice } \\
\text { Cognitive load theory (van } \\
\text { Merrienboer \& Sweller, } \\
\text { 2010) }\end{array}$ & $\begin{array}{l}\text { Interaction and feedback } \\
\text { Presence of patient }\end{array}$ & $\begin{array}{l}\text { Increasing authenticity of } \\
\text { instructional format did not } \\
\text { significantly improve students, } \\
\text { clinical reasoning performance. }\end{array}$ \\
\hline 14. & $\begin{array}{l}\text { Engstrom et al. } \\
\text { (2016) } \\
\text { Sweden }\end{array}$ & $\begin{array}{l}\text { Crossover RCT } \\
\text { To compare immersion in a basic } \\
\text { and a contextualized HPS } \\
\text { simulation using the Immersion } \\
\text { Score Rating Instrument. }\end{array}$ & $\begin{array}{l}\text { Fidelity as physical } \\
\text { resemblance and functional } \\
\text { task alignment (Hamstra et } \\
\text { al., 2014) }\end{array}$ & $\begin{array}{l}\text { Content drawn from real life } \\
\text { Interaction and feedback } \\
\text { Performance expectations } \\
\text { Preparation of environment } \\
\text { Logical, adaptive scenario } \\
\text { Sociological fidelity } \\
\text { Cueing }\end{array}$ & $\begin{array}{l}\text { Immersion was higher in the } \\
\text { contextualized simulation. } \\
\text { Events disrupting immersion } \\
\text { (instructor interventions, jumps in } \\
\text { time and space) were more present } \\
\text { in the basic condition, whereas } \\
\text { signals of immersion (natural } \\
\text { interaction with the manikin) were } \\
\text { more frequent in the contextualized } \\
\text { simulation. }\end{array}$ \\
\hline 15. & $\begin{array}{l}\text { Escher et al. } \\
(2017) \\
\text { Sweden }\end{array}$ & $\begin{array}{l}\text { Descriptive qualitative study } \\
\text { To examine methods to deliver } \\
\text { extra scenario information in HPS } \\
\text { simulation }\end{array}$ & $\begin{array}{l}\text { Empirical studies of how } \\
\text { gaps between simulations } \\
\text { and clinical tasks emerge } \\
\text { and can be bridged (Paige } \\
\& \text { Morin, 2013; Rystedt \& } \\
\text { Sjoblom, 2012) }\end{array}$ & Cueing & $\begin{array}{l}\text { Four methods to convey information } \\
\text { to participants in simulation-based } \\
\text { training: } 1 \text { - a confederate involved } \\
\text { in the scenario; } 2 \text { - a bystander who } \\
\text { did not partake in the scenario; } 3 \text { - a } \\
\text { loudspeaker; 4- earpiece worn by } \\
\text { one of the learners). } \\
\text { The choice of method impacted } \\
\text { participants workflow, pace, and } \\
\text { team communication. }\end{array}$ \\
\hline 16. & $\begin{array}{l}\text { Falconer (2013) } \\
\text { United Kingdom }\end{array}$ & $\begin{array}{l}\text { Case study } \\
\text { To evaluate environmental health } \\
\text { students' experience of an accident } \\
\text { investigation and risk assessment } \\
\text { exercise in a virtual world }\end{array}$ & $\begin{array}{l}\text { Situated learning (Lave \& } \\
\text { Wenger, 1991) }\end{array}$ & $\begin{array}{l}\text { Content drawn from real life } \\
\text { Interaction and feedback } \\
\text { Performance expectations } \\
\text { Preparation of environment }\end{array}$ & $\begin{array}{l}\text { Thirteen factors affected the sense } \\
\text { of authenticity in the virtual world. } \\
\text { Positive factors: facilitation, } \\
\text { presence and authority, visual } \\
\text { realism, socialization, comparative } \\
\text { reality, engagement, active learning, } \\
\text { generalizability and enabling } \\
\text { learning from mistakes. } \\
\text { Negative factors: public image of } \\
\text { virtual worlds, lack of naturalism, } \\
\text { unrealistic graphics and lack of } \\
\text { tactile sense. }\end{array}$ \\
\hline 17. & $\begin{array}{l}\text { Friedman et al. } \\
\text { (1991) }\end{array}$ & $\mathrm{RCT}$ & $\begin{array}{l}\text { Design variants in computer } \\
\text { simulation: static VS }\end{array}$ & $\begin{array}{l}\text { Interaction and feedback } \\
\text { Logical, adaptive scenario }\end{array}$ & $\begin{array}{l}\text { Students' performance varied in } \\
\text { each format. Generally, students }\end{array}$ \\
\hline
\end{tabular}




\section{USA}

To compare the same simulated case in three formats (pedagogic, high-fidelity, problem-solving) in a computer-based simulation on students' performance dynamic, amount of

feedback presented to

learners, data elicitation (free entry VS choice menus)

\begin{tabular}{ll}
\hline 18. Goncalves et al. & $\begin{array}{l}\text { Exploratory case study } \\
\text { To explore the authenticity of an } \\
\text { immersive game involving } \\
\text { computer simulation and role-play } \\
\text { from the perspective of students }\end{array}$
\end{tabular}

19. $\begin{aligned} & \text { Hindmarsh et al. } \\ & \text { (2014) }\end{aligned}$

United Kingdom

Hotchkiss et al.
(2002)

USA
Qualitative (Ethnomethodology)

To explore how tutors and students attend to matters of realism in the (PTT and VP).

Observational study

To assess the authenticity of videotaped HPS crisis resource management simulations with nurse anesthesia students
Learners' perception of game authenticity from three points of view: realism (likeness with a real-life reference), coherence (internal coherence of the proposed situations) and relevance (with respect to learning goals)

Interactionist perspective: Interactionist practices

Realism of simulation training is organized by participants in their interactions Authenticity as credibility of the simulation Physical and psychological fidelity
Content drawn from real life Interaction and feedback Performance expectations Logical, adaptive scenario Sociological fidelity

Cueing

Learner experience

Interaction and feedback Performance expectations Preparation of environmen Logical, adaptive scenario Sociological fidelity using the pedagogical format (with a menu to elicit data from the patient) accessed more data but did less with it. Students using the problem-solving and high-fidelity versions (free entry) reported difficulties in accessing information.

Four attributes of authenticity: mission, mise en scène, user freedom, and interactions.

Students' judgments of authenticity were complex and specific, with the same cues resulting in opposite judgments.

Tutors routinely invoke real life (complexities and contingencies of clinical practice) in instructional corrections to compensate for the insufficiency of the simulator. Scenarios were rated as extremely realistic by raters.

Failure to mirror the operating room culture, high degrees of anticipation that something was about to go wrong, and brevity of the scenarios compromised the authenticity and realism of the simulations.

Stress and performance did not differ between the two conditions. Students perceived SP to be more realistic and more effective regarding communication skills. To compare students' stress and fidelity performance in SP and HPS fidelity

Interaction and feedback (2015)

Singapore simulations

22. Ker et al. (2006) Descriptive evaluation study To evaluate perception of the

United Kingdom realism of a ward simulation
Environmental fidelity Realism of simulation content
Content drawn from real life Interaction and feedback Performance expectations Preparation of environment Sociological fidelity exercise with $\mathrm{SP}$
Realistic components included the need to prioritize, tasks reflecting everyday work, team working, and handover. 


\section{Cueing}

\section{Krogh et al. \\ (2014)}

Denmark

24. Lee et al. (2019)

Hong Kong

\section{RCT}

To test if real-time, 2-min cycle during resuscitation training using HPS ensured better adherence to resuscitation guidelines

Constructivist grounded theory

To construct a theory of nursing students' high-fidelity simulationbased learning
Time fidelity

Fidelity as reproduction of real-world reaction, interactions, and responses

Psychological fidelity (INACSL Standards

Committee, 2016)
25. MacLean et al. (2019)

Australia
Mixed-methods

To investigate whether students' perceptions of realism influence their level of presence in SP simulation and learning outcomes
Realism as ability of environment, patient, and educators to suspend disbelief

Physical, conceptual, and psychological fidelity

(INACSL Standards

Committee, 2016)

\begin{tabular}{|c|c|c|}
\hline 26. & Mangold (2016) & Descriptive evaluation study \\
\hline & USA & $\begin{array}{l}\text { To evaluate learning outcomes of } \\
\text { SP simulations for teaching kidney } \\
\text { transplant patient education } \\
\text { techniques }\end{array}$ \\
\hline
\end{tabular}

Performance expectations

Interaction and feedback Performance expectations Preparation of environment Presence of patient Sociological fidelity

\section{Content drawn from real life}

Interaction and feedback

Presence of patient

Sociological fidelity

Learner experience

manikins, presence of observers, lack of familiarity with the environment, and lack of noises. The real-time group adhered better to the recommended 2-min cycle than the shortened-time group, suggesting that time is an important part of fidelity.

Theoretical model consisting of four processes and four influencing factors. Lack of psychological fidelity compromised learning.

Perceived realism and presence positively affected students' discharge communication skills.

\section{Authentic learning theory Interaction and feedback} (Knobloch, 2003)
Preparation of environment Presence of patient

Logical, adaptive scenario

\section{The environment added}

authenticity. The use of SP allowed for real-time, two-way

communication, and awareness of the human aspect of the situation.

The use of real educational resources increased relevance to practice.

\begin{tabular}{|c|c|c|c|c|c|}
\hline 27. & $\begin{array}{l}\text { Marei et al. } \\
\text { (2018) } \\
\text { Saudi Arabia }\end{array}$ & $\begin{array}{l}\text { Explanatory qualitative study } \\
\text { To assess students' perceptions of } \\
\text { VP scenarios for developing ethical } \\
\text { skills }\end{array}$ & $\begin{array}{l}\text { Situated learning } \\
\text { (situativity) theory } \\
\text { (Durning \& Artino, 2011) }\end{array}$ & $\begin{array}{l}\text { Content drawn from real life } \\
\text { Interaction and feedback } \\
\text { Preparation of environment } \\
\text { Logical, adaptive scenario }\end{array}$ & $\begin{array}{l}\text { High-fidelity VP scenarios were } \\
\text { perceived better than low-fidelity } \\
\text { scenarios for developing ethical } \\
\text { skills. }\end{array}$ \\
\hline 28. & $\begin{array}{l}\text { McKittrick et al. } \\
\text { (2018) } \\
\text { Australia }\end{array}$ & $\begin{array}{l}\text { Action research } \\
\text { To evaluate and revise an } \\
\text { interprofessional team training } \\
\text { session using HPS simulation for } \\
\text { pediatric resuscitation }\end{array}$ & $\begin{array}{l}\text { Fidelity refers to mannequin } \\
\text { capabilities, as well as } \\
\text { environmental and } \\
\text { psychological reality } \\
\text { (Beaubien \& Baker, 2004) }\end{array}$ & $\begin{array}{l}\text { Performance expectations } \\
\text { Preparation of environment } \\
\text { Sociological fidelity }\end{array}$ & $\begin{array}{l}\text { In situ team training in real-time } \\
\text { increased realism. Participants } \\
\text { sought diversity in their teams } \\
\text { (mixture of experienced and non- } \\
\text { experienced staff). }\end{array}$ \\
\hline
\end{tabular}


29. Meurling et al. Case-control study

(2014)

Sweden

\section{Mills et al.}

Australia

\section{Nanji et al.}

(2013)

USA

\begin{tabular}{lll} 
32. & Ney et al. (2010) & $\begin{array}{l}\text { perception of realism in HPS } \\
\text { simulation }\end{array}$ \\
& $\begin{array}{l}\text { Descriptive evaluation study } \\
\text { To describe the authenticity of an } \\
\text { immersive game (involving } \\
\text { computer simulation and role-play } \\
\text { students) and the perceived } \\
\text { authenticity by players }\end{array}$ \\
\hline 33. & $\begin{array}{l}\text { Redmond et al. } \\
\text { (2018) }\end{array}$ & $\begin{array}{l}\text { Descriptive evaluation study } \\
\text { To evaluate student perceived } \\
\text { learning gains in terms of } \\
\text { knowledge using digital learning } \\
\text { activities }\end{array}$ \\
\hline Ireland & $\begin{array}{l}\text { Qualitative (Ethnographic method) } \\
\text { To develop a conceptually driven } \\
\text { argument on the unarticulated } \\
\text { potential of simulation in }\end{array}$ \\
& Australia & $\begin{array}{l}\text { professional formation } \\
\text { (2015) }\end{array}$
\end{tabular}
performance, mental strain, and flow experience during in situ training using a low-fidelity or HPS simulation

Mixed-methods experimentation To compare the psychological immersion in low- and highenvironmental fidelity HPS simulations

\section{RCT}

To determine whether a visual and olfactory sensory change affected anesthesiologists' and residents'
Equipment, environmental, Interaction and feedback and psychological fidelity Performance expectations (Rehmann et al., 1995)

emotional/experiential fidelity

Realism is a perception of the individual

\section{Four attributes of}

authenticity: authenticity of character, feedback content, communication mode and channel, and constraints

\section{Authentic learning}

(Herrington \& Oliver, 2000)

Interactionist perspective:

Focus on actions and relationships between people and the material world
Preparation of environmen

Sociological fidelity

Cueing

Preparation of environment

\section{Sociological fidelity}

Learner experience

Performance expectations

Preparation of environmen Logical, adaptive scenario

Sociological fidelity

Interactionist practices

\section{Content drawn from real life}

Interaction and feedback

Performance expectations

Sociological fidelity

Content drawn from real life

Re

Performance was affected by the levels of equipment used. Trainees' experiences were similar in both conditions.

\section{High-environmental fidelity}

engendered immersion and a sense

of urgency; low-fidelity engendered assessment anxiety and slower

performance.

The visual and olfactory increment to physical fidelity did not affect subjects' ratings of fidelity,

perception of realism and engagement.

Authenticity is defined externally (perceived likeness with real life), internally (perceived internal coherence of the situations), didactically (perceived relevance to learning goals).

Reusable learning objects designed using real cases reflect the true complexity of wound care and increased students' perception of their wound care abilities.

Fidelity is an emergent, fragile, and resilient phenomenon shaped by materialities and forces that form the world of practice and the university classroom.

Simulation can produce agile practitioners who can navigate the unexpected.

\begin{tabular}{|c|c|c|c|c|}
\hline 35. & $\begin{array}{l}\text { Rystedt and } \\
\text { Sjoblom (2012) } \\
\text { Sweden }\end{array}$ & $\begin{array}{l}\text { Qualitative Study } \\
\text { (Ethnomethodology) } \\
\text { To contrast the use of two } \\
\text { simulators (screen based and HPS }\end{array}$ & $\begin{array}{l}\text { Interactionist perspective: } \\
\text { How simulations are } \\
\text { interactively established by } \\
\text { users }\end{array}$ & $\begin{array}{l}\text { Performance expectations } \\
\text { Preparation of environment } \\
\text { Presence of patient } \\
\text { Logical, adaptive scenario }\end{array}$ \\
\hline
\end{tabular}

\section{Participants experienced glitches in}

the understanding of the simulation, which they bridge through 
simulations) to explore

requirements to establish and

maintain authenticity representation

of clinical practice

\begin{tabular}{ll}
\hline $36 . \quad$ Sadideen et al. \\
\\
$(2014,2016)$
\end{tabular}

Mixed-methods design

To explore participants' perception

of the fidelity of a portable burn

United Kingdom

HPS simulation environmen

\section{Seale et al. \\ (2007)}

To analyze the characteristics of
simulated role-play encounters that

promote learning of communication

skills in general practitioners

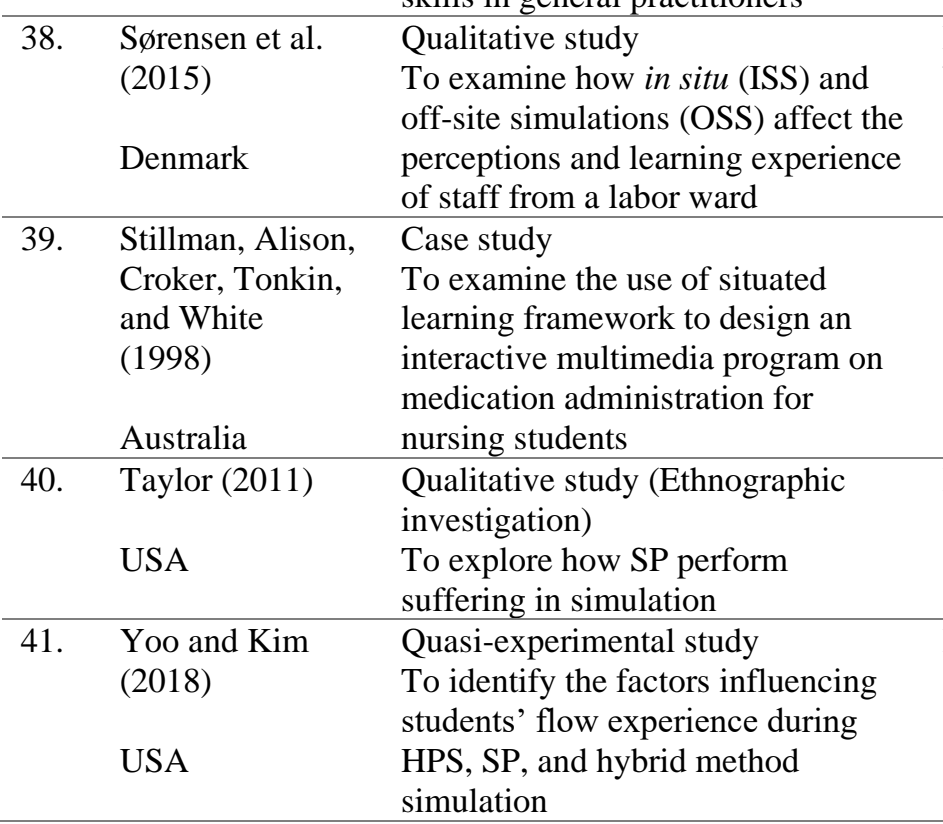

Sociological fidelity

Cueing

Interactionist practices orientation to the similarities and dissimilarities with real work.

The realism of the simulation was maintained through mutual orientation to what is good clinical practice.

Participants were able to behave as

in real resuscitation, including the performance of non-technical skills.

Experience felt authentic because it

had high psychological and social fidelity.

Presence of patient

Sociological fidelity

Interactionist perspective: Performance expectations

Participants sustain

Preparation of environment

authenticity and artificiality Presence of patient

through interactional work Interactionist practices

\section{Fidelity as faithfulness}

between two identity to

ensure transfer of learning

(Grierson, 2014)

Situated learning theory

(Brown et al., 1989)

Content drawn from real life

Interaction and feedback

Preparation of environment

Participants' negotiation of the simulations was observed in out-of-

frame utterances and enactment of the role-playing frame. Realism, achieved through mimicry, was responsible for learning.

Physical setting of the simulation is less important than performing in authentic roles.

resence of patien Sociological fidelity

Content drawn from real-life

Performance expectations

Preparation of environment

Logical, adaptive scenario

Realism of SP performance Content drawn from real life

Performance expectations

Presence of patient

Physical, psychological, Preparation of environment

and conceptual fidelity Presence of patient

(Paige \& Morin, 2013)
Key aspects of the framework were authentic contexts that reflect the way knowledge is used in real life and authentic activities that learners will be expected to engage in during their career.

SP performances reconcile a moral commitment to avoid suffering, with an aesthetic commitment to realistically portray it.

Perceived levels of fidelity influenced students' flow experience

NOTE. HPS = human patient simulator (manikin). PBL: Problem-based learning. PTT = partial task trained. RCT $=$ Randomized controlled trial. SP = standardized patient. VP = virtual patient. 
Table 2. Number of papers describing features of realism, fidelity, or authenticity operationalized by educators, experienced by learners, or related to interactionist practices in simulation

\begin{tabular}{lccc}
\hline \multicolumn{1}{c}{ Feature } & $\begin{array}{c}\text { Educators } \\
(n)\end{array}$ & $\begin{array}{c}\text { Learners } \\
(n)\end{array}$ & $\begin{array}{c}\text { Interactionist } \\
(n)\end{array}$ \\
\hline Content drawn from real-life & 13 & 4 & - \\
Interaction and feedback & 14 & 15 & 1 \\
Performance expectations & 9 & 13 & 1 \\
Preparation of the environment & 20 & 9 & 2 \\
Presence of patient & 10 & 4 & 2 \\
Logical, adaptive scenario & 8 & 5 & 1 \\
Sociological fidelity & 9 & 13 & 2 \\
Cueing & 10 & - & 2 \\
Learner experience & - & 6 & - \\
Interactionist practices & - & - & 5 \\
\hline
\end{tabular}

Table 3. Definitions of realism, fidelity, and authenticity chosen for this review

\begin{tabular}{ll}
\hline \multicolumn{1}{c}{ Concept } & \multicolumn{1}{c}{ Definition } \\
\hline Realism & $\begin{array}{l}\text { The quality or fact of representing a person, thing, or situation accurately in a } \\
\text { way true to life; this enables participants to act "as if" the situation or problem } \\
\text { was real (Lopreiato, 2016, p. 39). }\end{array}$ \\
Fidelity & $\begin{array}{l}\text { The degree to which the simulation replicates the real event and/or workplace; } \\
\text { this includes physical, psychological, and environmental elements. The ability } \\
\text { of the simulation to reproduce the reactions, interactions, and responses of the } \\
\text { real-world counterpart (Lopreiato, 2016, p. 18). }\end{array}$ \\
Authenticity & $\begin{array}{l}\text { An authentic learning environment provides a context that reflects the way } \\
\text { knowledge and skills will be used in real life. This includes a physical or }\end{array}$ \\
& virtual environment that resembles the real-world complexity and limitations \\
& (Gulikers et al., 2005, p. 509). \\
& $\begin{array}{l}\text { Interpretation of authenticity is individual (Bland et al., 2014, p. 1113). } \\
\text { Authenticity in the context of simulated learning is associated with realism of } \\
\text { which fidelity is a potential attribute. Authenticity, however, may bring realism } \\
\text { even if the learning environment is unrealistic and fidelity is low (p. 1115). }\end{array}$ \\
\hline
\end{tabular}

